\title{
Cold Pressor Test Influences the Cardio-Ankle Vascular Index in Healthy Overweight Young Adults
}

\author{
Supaporn Kulthinee ${ }^{a}$ Nitirut Nernpermpisooth $^{b}$ Montatip Poomvanicha $^{b}$ \\ Jidapa Satiphop $^{\mathrm{b}}$ Thizanamadee Chuang-ngu $^{\mathrm{b}}$ Napaporn Kaleeluan ${ }^{\mathrm{b}}$ \\ Kittisak Thawnashom ${ }^{c}$ Anuchit Manin ${ }^{d}$ Rosarin Kongchan ${ }^{d}$ \\ Kingkarn Yinmaroeng ${ }^{a}$ Peerapong Kitipawong ${ }^{a}$ Phatiwat Chotimol $^{b}$ \\ aChulabhorn International College of Medicine, Thammasat University, Pathum Thani, Thailand; bepartment \\ of Cardio-Thoracic Technology, Faculty of Allied Health Sciences, Naresuan University, Phitsanulok, Thailand; \\ 'Department of Medical Technology, Faculty of Allied Health Sciences, Naresuan University, Phitsanulok, Thailand; \\ ${ }^{d}$ Cardiac Centre, Naresuan University Hospital, Faculty of Medicine, Naresuan University, Phitsanulok, Thailand
}

\section{Keywords}

Arterial stiffness - Atherosclerosis - Augmentation index ·

Pulse wave velocity

\begin{abstract}
Objective: The cold pressor test (CPT) has been shown a potential sympathoexcitatory stimulus which increases aortic pulse wave velocity and the aortic augmentation index, suggesting that noninvasively, arterial stiffness parameters are altered by the CPT. The cardio-ankle vascular index (CAVI) is widely used for reflecting arterial stiffness, and the anklebrachial index $(\mathrm{ABI})$ for evaluating peripheral artery disease in obesity. We aimed to assess CAVI and $A B I$ in overweight young adults in the context of sympathetic activation by using the CPT. Methods: 160 participants were divided into 2 groups: 86 normal-weight (body mass index [BMI] 18.50$22.99 \mathrm{~kg} / \mathrm{m}^{2}$ ) and 74 overweight (BMI $\geq 23 \mathrm{~kg} / \mathrm{m}^{2}$ ). The CPT was performed by immersing a participant's left hand into cold water $\left(3-5^{\circ} \mathrm{C}\right)$ for $3 \mathrm{~min}$, and $\mathrm{CAVI}$ and $\mathrm{ABI}$ assessment.
\end{abstract}

karger@karger.com

(c) 2021 S. Karger AG, Basel

www.karger.com/pls

Karger
Results: At baseline, the CAVI in the overweight group was significantly less than that in the normal-weight group (5.79 \pm 0.85 vs. $6.10 \pm 0.85 ; p<0.05)$. The mean arterial pressure (MAP) for overweight was significantly greater than that for normal-weight subjects (93.89 \pm 7.31 vs. $91.10 \pm 6.72 ; p<$ 0.05). During the CPT, the CAVI increased in both normalweight and overweight subjects, the CAVI value was greater during the CPT in overweight subjects by $14.36 \%(6.62 \pm 0.95$ vs. $5.79 \pm 0.85, p<0.05)$ and in normal-weight subjects by $8.03 \%(6.59 \pm 1.20$ vs. $6.10 \pm 0.85, p<0.05)$ than those baseline values. The CPT evoked an increase in systolic blood pressure (SBP), diastolic BP (DBP), heart rate $\left(H R_{1}\right)$ and pulse pressure (PP) in both groups. After a 4-min CPT period, the CAVI returned values similar to the baseline values in both groups, and the SBP, DBP, MAP, and PP in overweight participants were significantly higher than those in normalweight participants. However, there was no significant difference in the $A B I$ at baseline, during CPT, and post-CPT in either group. Conclusions: Our results indicated that the CAVI was influenced by sympathetic activation response to 
the CPT in both normal-weight and overweight young adults. Specifically, during the CPT, the percentage change of the CAVI in overweight response was greater in normalweight participants than baseline values in each group. The $A B I$ was not found significantly associated with CPT. These findings suggesting that sympathoexcitatory stimulus by CPT influence CAVI results.

(c) 2021 S. Karger AG, Basel

\section{Introduction}

Overweight/obesity has become a major health issue worldwide as it has a negative effect on the individual's daily life and overall health [1]. Since excessive overweight/obesity is defined as fat accumulation, body mass index (BMI) is adopted as an indicator of body fat percentage. BMI is calculated from a person's height and weight [2-4]. Overweight/obesity is considered a highrisk factor for cardiovascular diseases (CVD) [5]. It is remarkable that arterial stiffness is a crucial factor causing CVD [6], yet the mechanisms responsible for overweight/ obesity associated with arterial stiffness are complex and not fully understood.

Arterial stiffness measurements were developed from the principle of pulse wave velocity (PWV) and blood pressure (BP) [7]. The cardio-ankle vascular index (CAVI) is a new arterial stiffness index $[7,8]$ that is clinically useful in predicting CVD, including hypertension, in obese patients [9]. The ankle-brachial index (ABI) has been widely used clinically to assess peripheral arterial disease in a variety of populations, such as those with diabetes mellitus, hypertension, metabolic syndrome, and obesity [10]. The line of evidence suggests that ABI could predict arterial stiffness-causing CVD [11]. However, there is a strong evidence based on a retrospective cross-sectional study in which 23,257 healthy Japanese subjects demonstrated an inverse linear relationship between CAVI and BMI, suggesting that increased adiposity leads to a decrease in arterial stiffness [12]. Also, children and adolescents have been reported to experience a negative association between obesity and arterial stiffening [13-15]. A negative association between CAVI and BMI was unexpected since obesity is considered as one of the important risk factors of atherosclerosis. The concept of "obesity paradox" is well-established in part provide an explanation for the unexpected pathogenesis of atherosclerosis. The possible mechanisms related to several factors such as the role of adipokines, genetic factor, hemodynamic factors and sheer stress, and the role of gut microbiota and inflammation in aortic athero- genesis [16]. Nevertheless, we still do not fully understand and need more elucidate in this complex multifactorial disease. Therefore, an early detection of atherosclerosis event in overweight young adult for prevention the progressive to CVD need to be considered.

It has been revealed that the cold pressor test (CPT) evaluates the sympathetic reactivity of the cardiovascular system during the immersion of a hand in cold water $[17$, 18]. The CPT has been used as a potential sympathoexcitatory stimulus in several studies [19-22]. The CPT also increases aortic PWV and the aortic augmentation index in young and older adults $[23,24]$, suggesting that noninvasively arterial stiffness parameters are altered by the $\mathrm{CPT}$. Regarding vascular tone changing influenced by the $\mathrm{CPT}$, this could affect the detection of atherosclerotic changes employing the CAVI and ABI. Taken together, we hypothesize that the sympathetic reactivity to the CPT should be observed the change in the CAVI and ABI value in this condition. Therefore, the aim of this study was to assess CAVI and ABI in overweight young adults during sympathetic reactivity to the $\mathrm{CPT}$.

\section{Materials and Methods}

\section{Study Population}

One hundred sixty young participants (20-37 years) were recruited for this study, which was conducted between August and December in 2018. The study protocol was approved by the Naresuan University Institutional Review Board with certificate approval number $401 / 2018$ following the completion of informed written consent by all participants. All methods were performed in accordance with the relevant guidelines and regulations. Among the participants, 74 were overweight (BMI ranged between 23.00 and $27.49 \mathrm{~kg} / \mathrm{m}^{2}$ ) and 86, normal-weight (BMI ranged between 18.50 and $22.99 \mathrm{~kg} / \mathrm{m}^{2}$ ). Medical questionnaires were used to assess health status. All participants were without evidence of hypertension, diabetes, dyslipidaemia, or CVDs. Baseline BP was less than $140 / 90 \mathrm{~mm} \mathrm{Hg}$ in all study participants.

\section{Experimental Protocol}

After the completion of the medical questionnaires for screening purposes, participant data were collected using standard medical procedures. Height, weight, and waist circumference were measured, and BP was measured after a 10 -min rest in a supine position. All cardiovascular parameter measurements were evaluated in a temperature-controlled room $\left(24-26^{\circ} \mathrm{C}\right)$.

\section{$C P T$, Cardiovascular Parameter, ABI, and CAVI}

\section{Measurement}

The CPT was performed by immersing the left hand up to the wrist into a container of ice water $\left(3-5^{\circ} \mathrm{C}\right)$ [25]. The participants' cardiovascular parameters, CAVI and ABI, were measured before the CPT as a baseline. These measurements were repeated twice more: during the test for $1 \mathrm{~min}$ and during recovery at $4 \mathrm{~min}$. 
Table 1. Characteristics of the study participants

\begin{tabular}{lccc}
\hline Parameter & $\begin{array}{c}\text { Normal weight } \\
(n=86)\end{array}$ & $\begin{array}{l}\text { Overweight } \\
(n=74)\end{array}$ & $p$ value \\
\hline Age, years & $21.71 \pm 2.43$ & $21.81 \pm 1.88$ & 0.77 \\
Male, $n(\%)$ & $41(47.7)$ & $33(44.6)$ & 0.70 \\
BMI, kg/m ${ }^{2}$ & $20.54 \pm 1.27$ & $27.30 \pm 3.58$ & $<0.001^{* *}$ \\
WHR & $0.80 \pm 0.05$ & $0.84 \pm 0.06$ & $<0.001^{* *}$ \\
Alcohol drinking, $n(\%)$ & & & \\
$\quad$ No & $33(38.37)$ & $31(41.89)$ & 0.65 \\
$\quad$ Active drinking & $53(61.63)$ & $43(58.12)$ & \\
Smoking, $n$ (\%) & $83(96.51)$ & & \\
$\quad$ No & $3(3.49)$ & $67(90.54)$ & 0.12 \\
$\quad$ Active smoking & $120.58 \pm 9.87$ & $127.26 \pm 10.89$ & $<0.001^{* *}$ \\
SBP, mm Hg & $73.95 \pm 6.30$ & $76.08 \pm 7.10$ & $0.046^{*}$ \\
DBP, mm Hg & $91.10 \pm 6.72$ & $93.89 \pm 7.31$ & $0.01^{*}$ \\
MAP, mm Hg & $73.09 \pm 9.48$ & $73.24 \pm 10.33$ & 0.92 \\
HR, bpm & $46.70 \pm 8.72$ & $51.18 \pm 9.08$ & $0.002^{*}$ \\
PP, mm Hg & $1.02 \pm 0.07$ & $1.03 \pm 0.08$ & 0.91 \\
ABI & $6.10 \pm 0.85$ & $5.79 \pm 0.85$ & $0.02^{*}$ \\
CAVI & & & \\
\hline
\end{tabular}

Values are expressed as mean \pm SD. BMI, body mass index; WHR, wrist-to-hip ratio; SBP, systolic blood pressure; DBP, diastolic blood pressure; HR, heart rate; PP, pulse pressure; MAP, mean arterial pressure; ABI, ankle-brachial index; CAVI, cardio-ankle vascular index. ${ }^{*} p$ value $<0.05$ versus normal weight. ${ }^{* *} p$ value $<0.001$ versus normal weight.
Both the CAVI and ABI can be measured noninvasively and were exanimated using the VaSera VS-1500N ${ }^{\circledR}$ Vascular Screening System (Fukuda Denshi, Tokyo, Japan). The assessment of the CAVI used electrocardiographic electrodes on both arms above the wrist and a microphone for phonocardiography on the sternum in the second intercostal space. Four BP cuffs were placed around the upper arms and the ankles. CAVI was calculated using the following equation: CAVI $=\mathrm{a}[(2 \rho \times 1 /(\mathrm{SBP}-\mathrm{DBP})) \times(\mathrm{In}$ $\left.\left.(\mathrm{SBP} / \mathrm{DBP}) \times \mathrm{PWV}^{2}\right)\right]+\mathrm{b}(\rho$ : density of blood; $\mathrm{a}$ and $\mathrm{b}$ : constants) [7]. ABI is calculated by dividing the SBP measured at the ankle by that at the arm [19]; also, HR and BP can both be measured with the vascular screening system VaSera $1500^{\circledR}$.

\section{Statistical Analysis}

Statistical analysis was carried out using SPSS for Windows, version 17.0 (SPSS, Inc., Chicago, IL, USA). Data are expressed as mean \pm SD. The normal distribution of the data was examined using the Kolmogorov-Smirnov test. Differences between 2 groups of continuous variables were analysed by using the independent $t$ test, and category variables were evaluated using the $\chi^{2}$ test. One-way ANOVA with repeated measures and pairwise comparisons with Bonferroni correction were used for the analysis of variables compared to the baseline. Statistical significance was defined as $p$ values $<0.05$.

\section{Results}

\section{Baseline Measurements}

The mean age was $21.71 \pm 2.43$ years in the normalweight group and $21.81 \pm 1.88$ years in the overweight group (Table 1). The mean BMI of the normal-weight group was $20.54 \pm 1.27 \mathrm{~kg} / \mathrm{m}^{2}$ and that of the overweight group was $27.30 \pm 3.58 \mathrm{~kg} / \mathrm{m}^{2}$, with age and sex matched in both groups. The baseline SBP, DBP, and mean arterial pressure (MAP and $\mathrm{PP}$ ) in overweight participants were significantly greater than those of normal-weight participants: $127.26 \pm 10.89$ versus $120.58 \pm 9.87, p<0.001 ; 76.08$ \pm 7.10 versus $73.95 \pm 6.30, p<0.05 ; 93.89 \pm 7.31$ versus $91.10 \pm 6.72, p<0.05$; and $51.18 \pm 9.08$ versus $46.70 \pm 8.72$, $p<0.05$, respectively. There was no significant difference in HR between groups (73.24 \pm 10.33 vs. $73.09 \pm 9.48)$. ABI was not significantly different between groups $(1.03 \pm 0.08$ vs. $1.02 \pm 0.07$ ), while the CAVI in the overweight group was significantly less than that in the normal-weight group $(5.79 \pm 0.85$ vs. $6.10 \pm 0.85 ; p<0.05)$.

\section{Cardiovascular Responses to CPT}

The cardiovascular responses to the CPT of the overweight group were significantly greater increases in SBP and $\mathrm{PP}$ than in the normal-weight group during the CPT and post-CPT at $0 \mathrm{~s}, 120 \mathrm{~s}$, and $240 \mathrm{~s}$ (Table 2). DBP and MAP increased significantly in both groups during CPT and $0 \mathrm{~s}$ and $240 \mathrm{~s}$ post-CPT. HR in the normal-weight group was significantly less than that in the overweight group during the CPT. However, all parameters returned to baseline at $120 \mathrm{~s}$ post-CPT.
Kulthinee et al. 
Table 2. Hemodynamic changes during and after CPT

\begin{tabular}{|c|c|c|c|c|c|}
\hline Parameter & Baseline & $\mathrm{CPT}$ & $0 \mathrm{~s}$ post-CPT & $120 \mathrm{~s}$ post-CPT & 240 s post-CPT \\
\hline \multicolumn{6}{|l|}{$\mathrm{SBP}, \mathrm{mm} \mathrm{Hg}$} \\
\hline Normal weight & $120.58 \pm 9.87$ & $140.56 \pm 12.18^{\#}$ & $124.24 \pm 10.07^{\#}$ & $120.24 \pm 9.29$ & $119.50 \pm 9.56$ \\
\hline Overweight & $127.26 \pm 10.89$ & $149.18 \pm 15.39^{\ddagger}$ & $131.46 \pm 10.74^{\ddagger}$ & $127.04 \pm 10.85$ & $126.62 \pm 11.19$ \\
\hline$p$ value & $<0.001^{* *}$ & $<0.001^{* *}$ & $<0.001^{* *}$ & $<0.001^{* *}$ & $<0.001^{* *}$ \\
\hline \multicolumn{6}{|l|}{$\mathrm{DBP}, \mathrm{mm} \mathrm{Hg}$} \\
\hline Normal weight & $73.95 \pm 6.30$ & $91.74 \pm 9.62^{\#}$ & $77.30 \pm 6.26^{\#}$ & $74.24 \pm 6.67$ & $72.53 \pm 6.16$ \\
\hline Overweight & $76.08 \pm 7.10$ & $95.07 \pm 10.47^{\ddagger}$ & $78.86 \pm 7.79^{\ddagger}$ & $74.18 \pm 13.97$ & $75.27 \pm 7.46$ \\
\hline$p$ value & $0.046^{*}$ & $0.04^{*}$ & 0.16 & 0.10 & $0.01^{*}$ \\
\hline \multicolumn{6}{|l|}{ MAP, mm Hg } \\
\hline Normal weight & $91.10 \pm 6.72$ & $108.99 \pm 9.35^{\#}$ & $94.08 \pm 6.42^{\#}$ & $91.76 \pm 6.58$ & $90.52 \pm 6.52$ \\
\hline Overweight & $93.89 \pm 7.31$ & $112.88 \pm 15.36^{\ddagger}$ & $97.46 \pm 7.22^{\ddagger}$ & $92.92 \pm 12.13$ & $93.18 \pm 6.67$ \\
\hline$p$ value & $0.01^{*}$ & 0.05 & $0.002^{*}$ & 0.44 & $0.01^{*}$ \\
\hline \multicolumn{6}{|l|}{ HR, bpm } \\
\hline Normal weight & $73.09 \pm 9.48$ & $82.21 \pm 12.63^{\#}$ & $75.81 \pm 11.46^{\#}$ & $73.70 \pm 9.87$ & $72.99 \pm 9.32$ \\
\hline Overweight & $73.24 \pm 10.33$ & $78.38 \pm 9.91^{*}$ & $73.35 \pm 10.88$ & $72.57 \pm 10.09$ & $72.12 \pm 10.83$ \\
\hline$p$ value & 0.92 & $0.04^{*}$ & 0.17 & 0.48 & 0.59 \\
\hline \multicolumn{6}{|l|}{$\mathrm{PP}, \mathrm{mm} \mathrm{Hg}$} \\
\hline Normal weight & $46.70 \pm 8.72$ & $48.85 \pm 9.01$ & $46.94 \pm 7.56$ & $46.00 \pm 8.49$ & $46.97 \pm 7.84$ \\
\hline Overweight & $51.18 \pm 9.08$ & $54.41 \pm 10.70^{\ddagger}$ & $51.85 \pm 10.05$ & $51.57 \pm 9.98$ & $51.84 \pm 9.02$ \\
\hline$p$ value & $0.002^{*}$ & $<0.001^{* *}$ & $0.001^{*}$ & $<0.001^{* *}$ & $<0.001^{* *}$ \\
\hline
\end{tabular}

Values are expressed as mean \pm SD. SBP, systolic blood pressure; DBP, diastolic blood pressure; MAP, mean arterial pressure; $\mathrm{HR}$, heart rate; $\mathrm{PP}$, pulse pressure; $\mathrm{CPT}$, cold pressor test. ${ }^{*} p$ value $<0.05$ versus normal weight. ${ }^{* *} p$ value $<0.001$ versus normal weight. ${ }^{*} p$ value $<0.05$ versus normal weight at baseline. ${ }^{*} p$ value $<0.05$ versus overweight at baseline.

Fig. 1. $\mathrm{ABI}$ at baseline, CPT, 0 s post-CPT, 120 s post-CPT and 240 s post-CPT. In Fig. 1 , ABI was not shown to be significantly different in any measurement period in both groups. Values are expressed as mean $\pm \mathrm{SD}$. CPT, cold pressor test. ABI, anklebrachial index.

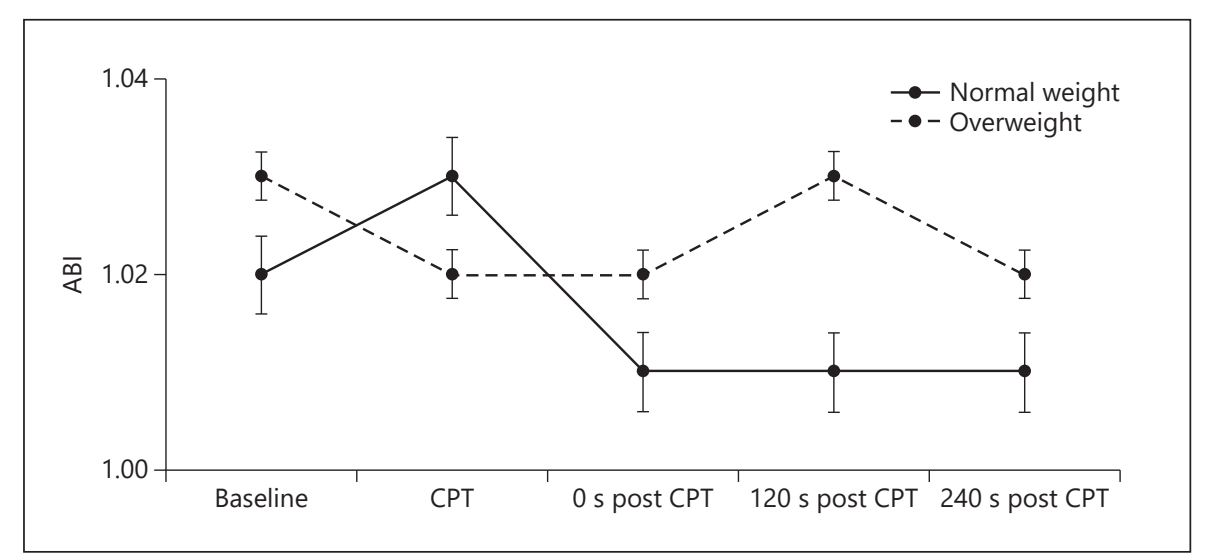

\section{Discussion}

The major finding of this study was that, in the baseline condition, overweight subjects had higher BP, lower CAVI, and no difference in ABI compared to normalweight subjects. Furthermore, sympathetic reactivity to the CPT in overweight participants contributed to increased CAVI, which led the overweight group to have a similar value to the normal-weight group. Therefore, participants $(6.59 \pm 1.20$ vs. $6.10 \pm 0.85, p<0.05)$ (Fig. 2 ). 
Table 3. ABI and CAVI changes during and after CPT

\begin{tabular}{|c|c|c|c|c|c|}
\hline Parameter & Baseline & $\mathrm{CPT}$ & $\begin{array}{l}0 \mathrm{~s} \\
\text { post-CPT }\end{array}$ & $\begin{array}{l}120 \mathrm{~s} \\
\text { post-CPT }\end{array}$ & $\begin{array}{l}240 \mathrm{~s} \\
\text { post-CPT }\end{array}$ \\
\hline \multicolumn{6}{|l|}{$\mathrm{ABI}$} \\
\hline Normal weight & $1.02 \pm 0.07$ & $1.03 \pm 0.07$ & $1.01 \pm 0.07$ & $1.01 \pm 0.07$ & $1.01 \pm 0.06$ \\
\hline Overweight & $1.03 \pm 0.08$ & $1.02 \pm 0.10$ & $1.02 \pm 0.08$ & $1.03 \pm 0.07$ & $1.02 \pm 0.08$ \\
\hline$p$ value & 0.91 & 0.93 & 0.67 & 0.32 & 0.31 \\
\hline \multicolumn{6}{|l|}{ CAVI } \\
\hline Normal weight & $6.10 \pm 0.85$ & $6.59 \pm 1.20^{\#}$ & $6.38 \pm 0.92^{\#}$ & $5.97 \pm 0.91$ & $5.94 \pm 0.88$ \\
\hline Overweight & $5.79 \pm 0.85$ & $6.62 \pm 0.95^{\ddagger}$ & $6.17 \pm 1.04^{\ddagger}$ & $5.93 \pm 1.14^{\ddagger}$ & $5.77 \pm 0.85$ \\
\hline$p$ value & $0.02 *$ & 0.84 & 0.18 & 0.82 & 0.20 \\
\hline
\end{tabular}

Values are expressed as mean \pm SD. ABI, ankle-brachial index; CAVI, cardio-ankle vascular index; CPT, cold pressor test. * $p$ value $<0.05$ versus normal weight. ${ }^{*} p$ value $<0.05$ versus normal weight at baseline. ${ }^{\ddagger} p$ value $<0.05$ versus overweight at baseline.
Table 4. Percentage change of ABI and CAVI during CPT

\begin{tabular}{lllr}
\hline Parameter & Baseline & CPT & $\%$ \\
\hline ABI & & & \\
$\quad$ Normal weight & $1.02 \pm 0.07$ & $1.03 \pm 0.07$ & 0.98 \\
$\quad$ Overweight & $1.03 \pm 0.08$ & $1.02 \pm 0.10$ & 0.97 \\
$\quad \begin{array}{l}p \text { value } \\
\text { CAVI }\end{array}$ & 0.91 & 0.93 & \\
$\quad$ Normal weight & $6.10 \pm 0.85$ & $6.59 \pm 1.20^{\#}$ & 8.03 \\
$\quad \begin{array}{l}\text { Overweight } \\
\quad \text { value }\end{array}$ & $5.79 \pm 0.85$ & $6.62 \pm 0.95^{*}$ & 14.36 \\
& $0.02^{*}$ & 0.84 & \\
\hline
\end{tabular}

Values are expressed as mean $\pm \mathrm{SD}$. ABI, ankle-brachial index; CAVI, cardio-ankle vascular index; CPT, cold pressor test. * $p$ value $<0.05$ versus normal weight. ${ }^{\#} p$ value $<0.05$ versus normal weight at baseline. ${ }^{\ddagger} p$ value $<0.05$ versus overweight at baseline.

lower CAVI value observed in baseline of the overweight group may not indicate atherosclerosis. This result could be used for the detection of early atherosclerotic changes in overweight young adult employing CAVI examination influenced by the CPT.

Our baseline results showed overweight group have significantly higher SBP, DBP, MAP, and PP without increases in HR. These results imply augmented basal sympathetic nerve activity (SNA)-driven peripheral vasoconstriction in overweight individuals. Increased baseline SNA has been reported in obesity, and chronic baseline sympathetic overactivity likely contributes to the mechanism underlying the development of arterial stiffness [7]. Other studies have demonstrated that BMI and waist circumference increased BP parameters, in which a higher prevalence of hypertension in young adult with excessive weight $[26,27]$. This result is important that even during young adult, having excessive weight predisposes to the development of hypertension.

The comparison between moments of the CPT, our study found that SBP, DBP, MAP, and PP increased during the CPT and returned to baseline post-CPT in both groups. Comparing between groups during the $\mathrm{CPT}$, the overweight participants had significantly higher values in these parameters. This evidence suggests that sympathetic reactivity to CPT in overweight groups greater than normal-weight group. On the other hand, the results indicated that potential sympathetic reactivity to $\mathrm{CPT}$ in overweight groups. Other study has highlighted the sympathoexcitatory stimulus by cold stressor significantly increases the sympathetic nerve reactivity in overweight individuals [28], suggesting that these abnormalities in sympathetic responses during the CPT may precede the development of CVD in the overweight group.

Our finding showed that overweight subjects had lower CAVI at baseline, which was consistent with the finding by Nagayama et al. [12]. Their study reported that healthy Japanese subjects demonstrated an inverse linear relationship between CAVI and BMI. Lower CAVI values in obese healthy people may be explained by hemodynamic factor and sheer stress. An increase in aortic and iliac arterial diameters is associated with an increase BMI $[29,30]$. Since sheer stress is inversely to the cross-sectional area of the vessel and cross-sectional area is related to diameter. If the diameter changes even small increase of the aorta, this will result in a significant decrease in endothelial cell sheer stress which associated with a paradoxically decreased CAVI.

Increased CAVI value during the CPT was found in both groups. In this regard, the mechanism may be mediated the relationship between SNA and vessel wall me- 
Fig. 2. CAVI at baseline, CPT, 0 s postCPT, 120 s post-CPT, and $240 \mathrm{~s}$ post-CPT. In Fig. 2, CAVI increased in both the normal-weight and the overweight participants during CPT. Values are expressed as mean $\pm \mathrm{SD}$. CPT, CPT. ${ }^{*} p$ value $<0.05$ versus normal weight, ${ }^{\#} p$ value $<0.05$ versus normal weight at baseline and ${ }^{\ddagger} p$ value $<0.05$ versus Overweight at baseline. CPT, cold pressor test; CAVI, cardio-ankle vascular index.

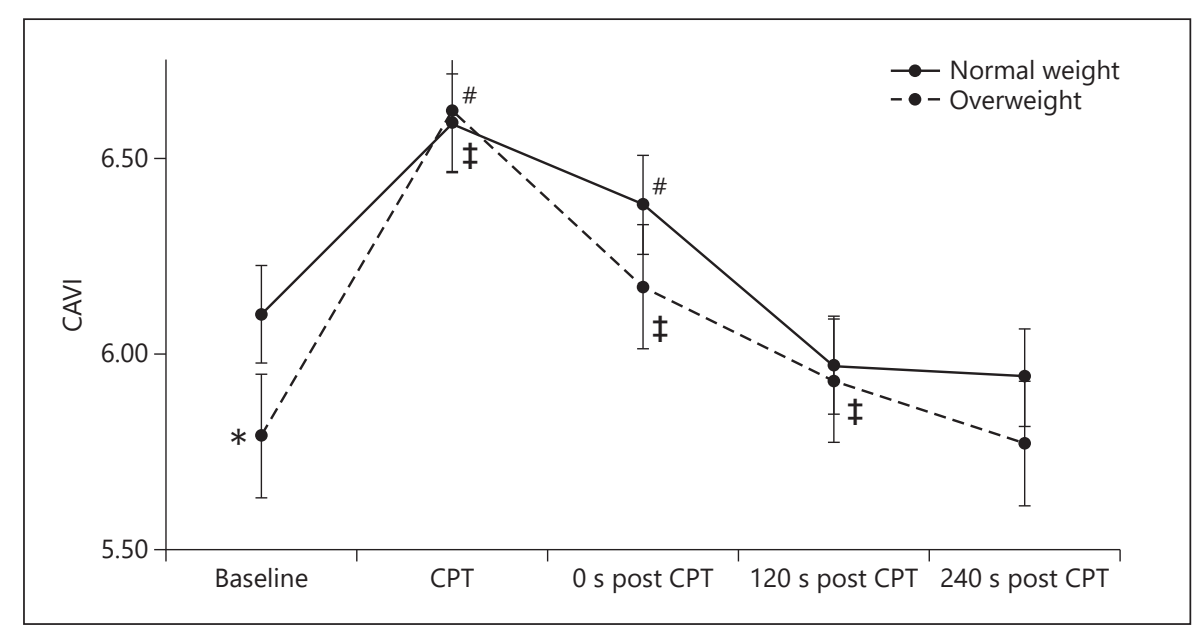

chanical properties. SNA is directly activated by the CPT, SNA regulated the changes in vascular tone and mediators such as nitric oxide, endothelin 1 and norepinephrine, are known to affect arterial wall stiffness [31]. Likewise, data obtained in aortic PWV upon central and peripheral pressor responses to sympathetic activation via the CPT, both central and peripheral aortic PWV increased in all subjects during the CPT [32]. PWV is a commonly used index of arterial stiffness. However, PWV essentially changes according to changes in BP at the measuring time [33]. Similarly, brachial-ankle PWV is affected by BP $[34,35]$. Thus, PWV may not be an appropriate index for research studying the effect of $\mathrm{BP}$ on arterial stiffness. The CAVI was developed by applying formula using PWV, as an index reflecting arterial stiffness. CAVI is more closely correlated to aortic distensibility than PWV [36]. Our study was to examine the influence of arterial stiffness upon the CPT; therefore, CAVI is an appropriate index for the study.

Our finding revealed the important results that CAVI in overweight participants during acute sympathetic activation by CPT response increased by $14.36 \%$, while in normal-weight ones, it increased by $8.03 \%$, which means that the overweight response was 1.8 times greater than that of normal-weight participants. Once SNA was stimulated, there seemed to be greater reactivity in overweight subjects. Our observed is necessary to establish the precise mechanism by which sympathetic hyper-reactivity to the CPT in the overweight group compared to normalweight group. It is possible that increased baseline SNA, which has been reported in obesity $[37,38]$, and chronic baseline sympathetic overactivity likely contributes to the mechanism underlying the development of arterial stiffness [7]. Thus, SNA alteration in obesity may be a poten-

Effect of Cold Pressor Test on CAVI and $\mathrm{ABI}$ tial underlying mechanism that contributes to arterial stiffness. This may be especially important for the CAVI assessment's concurrent with the CPT in the earliest stages of excessive body weight for consideration of the development of overweight-related arterial stiffness. Consequently, lower CAVI value observed in overweight young adult may not indicate the absence of vessel damage leading to arterial stiffness. We suggest considering sympathetic activation concurrent with interpreting CAVI. Although $\mathrm{ABI}$ is one of the noninvasive tools for predicting arterial stiffness, several studies shows that it is more clinically significant for peripheral artery diseases than for arterial stiffness assessment $[11,39]$. Our finding did not find a significant difference in the ABI between groups in the study. This finding could indicate no harmful effect of overweight in young age on peripheral artery function. Notably, being based on sympathetic activation by the $\mathrm{CPT}$, the $\mathrm{ABI}$ was not influenced in this condition.

The limitation of this study was that we did not measure direct SNA at baseline; therefore, we were unable to quantify SNA directly. However, cardiovascular parameters increased in overweight subjects, so it is reasonable to posit that overweight significantly increases SNA at baseline. Additionally, in the medical history health questionnaire, we did not exclude active alcohol drinking and smoking. This may influence vascular health. These conditions should be followed up in the future.

In conclusion, our study demonstrates that overweight is associated with BP increasing but CAVI decreasing in the baseline condition. Particularly, we extend the knowledge that the CPT has an influence on CAVI, suggesting that sympathetic reactivity in response to CPT should be considered a concurrent arterial stiffness study in overweight young adults. 


\section{Acknowledgment}

We would like to thank Mr. Kevin Mark Roebl, Naresuan University Language Centre (NULC), Naresuan University for manuscript editing and correction.

\section{Statement of Ethics}

All procedures performed in studies involving human participants were in accordance with the ethical standards of the institutional and national research committee and with the $1964 \mathrm{Hel}-$ sinki Declaration. The study protocol was approved by the Naresuan University Institutional Review Board with certificate approval number 401/2018 following the completion of informed written consent by all participants.

\section{Conflict of Interest Statement}

The authors have no conflicts to declare.

\section{Funding Sources}

This study was supported by the Faculty of Allied Health Sciences Fund at Naresuan University.

\section{Author Contributions}

Design of experiments, evaluation, and discussion of results, and writing the manuscript: S.K.; design of experiments: N.N.; data collection, J.S., T.C., and N.K.; computational framework and data analysis: K.T., A.M., R.K., K.Y., M.P., and P.K.; and advising on all research, design of experiments, evaluation and discussion of results, and writing the manuscript: P.C.

\section{References}

1 Chooi YC, Ding C, Magkos F. The epidemiology of obesity. Metabolism. 2019;92:6-10.

2 Flegal KM, Shepherd JA, Looker AC, Graubard BI, Borrud LG, Ogden CL, et al. Comparisons of percentage body fat, body mass index, waist circumference, and waist-stature ratio in adults. Am J Clin Nutr. 2009;89(2): 500-8.

3 Gallagher D, Visser M, Sepúlveda D, Pierson RN, Harris T, Heymsfield SB. How useful is body mass index for comparison of body fatness across age, sex, and ethnic groups? Am J Epidemiol. 1996;143(3):228-39.

4 Ranasinghe C, Gamage P, Katulanda P, Andraweera N, Thilakarathne S, Tharanga P. Relationship between body mass index (BMI) and body fat percentage, estimated by bioelectrical impedance, in a group of Sri Lankan adults: a cross sectional study. BMC Public Health. 2013;13:797.

5 Vaneckova I, Maletínská L, Behuliak M, Nagelová V, Zicha J, Kuneš J. Obesity-related hypertension: possible pathophysiological mechanisms. J Endocrinol. 2014;223(3):R6378.

6 Bonarjee VVS. Arterial stiffness: a prognostic marker in coronary heart disease. Available methods and clinical application. Front Cardiovasc Med. 2018;5:64.

7 Shirai K, Utino J, Otsuka K, Takata M. A novel blood pressure-independent arterial wall stiffness parameter; cardio-ankle vascular index (CAVI). J Atheroscler Thromb. 2006; 13(2):101-7.

8 Satoh N, Shimatsu A, Kato Y, Araki R, Koyama K, Okajima T, et al. Evaluation of the cardio-ankle vascular index, a new indicator of arterial stiffness independent of blood pressure, in obesity and metabolic syndrome. Hypertens Res. 2008;31(10):1921-30.
9 Satoh-Asahara N, Kotani K, Yamakage H, Yamada T, Araki R, Okajima T, et al. Cardioankle vascular index predicts for the incidence of cardiovascular events in obese patients: a multicenter prospective cohort study (Japan obesity and metabolic syndrome study: JOMS). Atherosclerosis. 2015;242(2): 461-8.

10 Rac-Albu M, Iliuta L, Guberna SM, Sinescu C. The role of ankle-brachial index for predicting peripheral arterial disease. Maedica. 2014; 9(3):295-302.

11 Hendriks EJ, Westerink J, de Jong PA, de Borst GJ, Nathoe HM, Mali WP, et al. Association of high ankle brachial index with incident cardiovascular disease and mortality in a high-risk population. Arterioscler Thromb Vasc Biol. 2016;36(2):412-7.

12 Nagayama D, Imamura H, Sato Y, Yamaguchi $\mathrm{T}$, Ban N, Kawana H, et al. Inverse relationship of cardioankle vascular index with BMI in healthy Japanese subjects: a cross-sectional study. Vasc Health Risk Manag. 2017;13:1-9.

13 Charakida M, Jones A, Falaschetti E, Khan T, Finer N, Sattar N, et al. Childhood obesity and vascular phenotypes: a population study. J Am Coll Cardiol. 2012;60(25):2643-50.

14 Dangardt F, Osika W, Volkmann R, Gan LM, Friberg P. Obese children show increased intimal wall thickness and decreased pulse wave velocity. Clin Physiol Funct Imaging. 2008; 28(5):287-93.

15 Lurbe E, Torro I, Garcia-Vicent C, Alvarez J, Fernández-Fornoso JA, Redon J. Blood pressure and obesity exert independent influences on pulse wave velocity in youth. Hypertension. 2012;60(2):550-5.

16 Barth RF, Maximilian Buja L, Cao L, Brodsky SV. An obesity paradox: increased body mass index is associated with decreased aortic ath- erosclerosis. Curr Hypertens Rep. 2017;19(7): 55.

17 Casey DP, Braith RW, Pierce GL. Changes in central artery blood pressure and wave reflection during a cold pressor test in young adults. Eur J Appl Physiol. 2008;103(5):539-43.

18 Mourot L, Bouhaddi M, Regnard J. Effects of the cold pressor test on cardiac autonomic control in normal subjects. Physiol Res. 2009; 58(1):83-91.

19 Aboyans V, Criqui MH, Abraham P, Allison MA, Creager MA, Diehm C, et al. Measurement and interpretation of the ankle-brachial index: a scientific statement from the American heart association. Circulation. 2012; 126(24):2890-909.

20 Hubli M, Bolt D, Krassioukov AV. Cold pressor test in spinal cord injury-revisited. Spinal Cord. 2018;56(6):528-37.

21 Stuckless TJ, Pyke KE. The impact of a cold pressor test on brachial artery handgrip exercise-induced flow-mediated dilation. Vasc Med. 2015;20(5):409-16.

22 Usselman CW, Wakefield PK, Skow RJ, Stickland MK, Chari RS, Julian CG, et al. Regulation of sympathetic nerve activity during the cold pressor test in normotensive pregnant and nonpregnant women. Hypertension. 2015;66(4):858-64.

23 Bellinazzi VR, Sposito AC, Schreiber R, Mill JG, Krieger JE, Pereira AC, et al. Response to cold pressor test predicts long-term changes in pulse wave velocity in men. Am J Hypertens. 2014;27(2):157-61.

24 Kalfon R, Campbell J, Alvarez-Alvarado S, Figueroa A. Aortic hemodynamics and arterial stiffness responses to muscle metaboreflex activation with concurrent cold pressor test. Am J Hypertens. 2015; 28(11):1332-8. 
25 Zhao Q, Bazzano LA, Cao J, Li J, Chen J, Huang J, et al. Reproducibility of blood pressure response to the cold pressor test: the GenSalt study. Am J Epidemiol. 2012; 176(Suppl 7):S91-8.

26 Dua S, Bhuker M, Sharma P, Dhall M, Kapoor S. Body mass index relates to blood pressure among adults. N Am J Med Sci. 2014;6(2):8995.

27 Linderman GC, Lu J, Lu Y, Sun X, Xu W, Nasir $\mathrm{K}$, et al. Association of body mass index with blood pressure among 1.7 million Chinese adults. JAMA Netw Open. 2018;1(4): e181271.

28 Park J, Middlekauff HR, Campese VM. Abnormal sympathetic reactivity to the cold pressor test in overweight humans. Am J Hypertens. 2012;25(12):1236-41.

29 Cowan GS Jr, Defibaugh N, White T, Hiler ML, Somes G. Aorta and iliac arterial sizes in pre-operative morbidly obese patients: a preliminary report. Obes Surg. 1991;1(2):155-9.
30 Davis AE, Lewandowski AJ, Holloway CJ, Ntusi NA, Banerjee R, Nethononda R, et al. Observational study of regional aortic size referenced to body size: production of a cardiovascular magnetic resonance nomogram. J Cardiovasc Magn Reson. 2014;16:9.

31 Bruno RM, Ghiadoni L, Seravalle G, Dell'oro R, Taddei S, Grassi G. Sympathetic regulation of vascular function in health and disease. Front Physiol. 2012;3:284.

32 Borner A, Murray K, Trotter C, Pearson J. Baseline aortic pulse wave velocity is associated with central and peripheral pressor responses during the cold pressor test in healthy subjects. Physiol Rep. 2017;5(14).

33 Sun CK. Cardio-ankle vascular index (CAVI) as an indicator of arterial stiffness. Integr Blood Press Control. 2013;6:27-38.

34 Takahashi M, Shiba T, Hirano K, Hitsumoto T, Shirai K. Acute decrease of cardio-ankle vascular index with the administration of beraprost sodium. J Atheroscler Thromb. 2012;19(5):479-84.

35 Ibata J, Sasaki H, Kakimoto T, Matsuno S, Nakatani M, Kobayashi M, et al. Cardio-ankle vascular index measures arterial wall stiffness independent of blood pressure. Diabetes Res Clin Pract. 2008;80(2):265-70.
36 Boardman H, Lewandowski AJ, Lazdam M, Kenworthy Y, Whitworth P, Zwager CL, et al. Aortic stiffness and blood pressure variability in young people: a multimodality investigation of central and peripheral vasculature. J Hypertens. 2017;35(3):513-22.

37 Esler M, Straznicky N, Eikelis N, Masuo K, Lambert G, Lambert E. Mechanisms of sympathetic activation in obesity-related hypertension. Hypertension. 2006;48(5):787-96.

38 Thorp AA, Schlaich MP. Relevance of sympathetic nervous system activation in obesity and metabolic syndrome. J Diabetes Res. 2015;2015:341583.

39 Saji N, Kimura K, Yagita Y, Kawarai T, Shimizu H, Kita Y. Comparison of arteriosclerotic indicators in patients with ischemic stroke: ankle-brachial index, brachial-ankle pulse wave velocity and cardio-ankle vascular index. Hypertens Res. 2015;38(5):323-8. 